J. Lake Sci. (湖泊科学), 2014, 26(3):340-348

http: //www. jlakes.org. E-mail : jlakes@niglas.ac.cn

(C) 2014 by Journal of Lake Sciences

\title{
水位波动对长江中下游湖泊湖滨带底质环境的影响
}

\author{
丁庆章 ${ }^{1,2}$, 刘学勤 $^{1 * *}$, 张晓可 $^{1,2}$ \\ ( 1 : 中国科学院水生生物研究所,武汉 430072) \\ (2: 中国科学院大学, 北京 100049$)$
}

\begin{abstract}
摘 要: 以长江中下游湖泊为对象, 研究了水位波动对湖滨带底质环境的影响. 结果表明, 底质环境参数沿高程梯度变化 明显. 底质含水率沿高程梯度增加而减小, $\mathrm{pH}$ 值沿高程梯度变化不大, 有机质、总氮和总磷沿高程梯度呈先增大后减小的 趋势. 底质环境参数的季节变化也较大. 分析表明, 水位波动幅度、淹没深度、高水位持续时间等对湖滨带底质环境有较 大影响. 在中等波动幅度下, 底质参数沿高程的变异系数最大, 表明此时湖滨带底质异质性较高. 夏季湖滨带淹没时间越 长、淹没深度越大, 底质养分流失越快. 高水位持续时间越长, 底质 $\mathrm{pH}$ 值变化就越大、营养盐流失越快. 本研究结果可为 湖滨带生态修复及管理提供依据.
\end{abstract}

关键词: 水位波动;湖滨带;底质;长江中下游

\section{Impacts of water level fluctuations on substrate environments of lakeshore zone of the lakes in the middle and lower reaches of the Yangtze River}

\author{
DING Qingzhang ${ }^{1,2}$, LIU Xueqin ${ }^{1}$ \& ZHANG Xiaoke ${ }^{1,2}$ \\ (1: Institute of Hydrobiology, Chinese Academy of Sciences, Wuhan 430072, P. R. China) \\ (2: University of Chinese Academy of Sciences, Beijing 100049, P. R. China)
}

\begin{abstract}
The present paper dealt with the impacts of water level fluctuations on the lakeshore substrate environments of the shallow lakes in the middle and lower reaches of the Yangtze River. The results showed that substrate environments changed greatly with the elevation gradients. Moisture contents of substrate decreased as the elevation increased, and $\mathrm{pH}$ value changed little, while contents of organic matter, total nitrogen and total phosphorus in substrate increased at first and then decreased. Also, substrate environments showed clear seasonal dynamics. Analyses showed that the amplitude of water level fluctuations, submergence depth, and duration of high water level had great impacts on the substrates. The coefficients of variation of substrate parameters were the largest in the medium amplitude, indicating that the highest heterogeneity of substrate occurred under such a condition. Substrate nutrients would be lost at an increasing pace with the increase of time and depth submerged during summer. If the duration of high water level was long, the $\mathrm{pH}$ values would be changed greater and the nutrients would be lost faster. Our results offered a scientific foundation for ecological restoration and management of the lakeshore.
\end{abstract}

Keywords: Water level fluctuations; lakeshore; substrate; the middle and lower reaches of the Yangtze River

水位波动是湖泊生态系统结构与功能的重要控制因素 ${ }^{[-2]}$. 水位波动不仅可以影响湖泊生物的生长、分 布, 也在湖泊物理、化学过程中起着重要作用 ${ }^{[3]}$. 湖滨带是湖泊水位季节性变化形成的陆地生态系统和湖泊 生态系统的交错带, 具有重要的生态和服务功能,如消解和滞留污染物、稳固湖岸与维持清水稳态、支持区 域生物群落等 ${ }^{[4-8]}$. 因此, 研究水位波动对湖滨带生态系统的影响对湖滨带保护和修复具有重要意义.

近 20 年来,国际上有关水位波动对湖滨带生态系统影响的研究逐渐增多. 现有研究集中于水位波动对 湖滨带植物群落的影响及机制分析 ${ }^{[9-10]}$, 而对于水位波动与湖滨带底质环境之间的关系研究较少且缺乏系

* 国家自然科学基金项目 (41001117) 和国家水体污染控制与治理科技重大专项项目 (2012ZX07103003) 联合资助. 2013-04-23 收稿;2013-09-16 收修改稿. 丁庆章(1987 ), 男, 硕士研究生;E-mail :dqzh06@ 126. com.

** 通信作者;E-mail:xqliu@ihb. ac. cn. 
统性 ${ }^{[1-12]}$. 相关研究在国内十分缺乏, 仅有少量报道 ${ }^{[13-14]}$.

本文以长江中下游湖泊为对象, 较为系统地研究了水位波动对湖滨带底质环境的影响, 以期为湖滨带 生态系统的管理提供科学依据.

\section{1 材料和方法}

\section{1 研究湖泊概况}

本研究选取长江中下游 5 个水位波动差异较大的湖泊开展工作 (图 1).

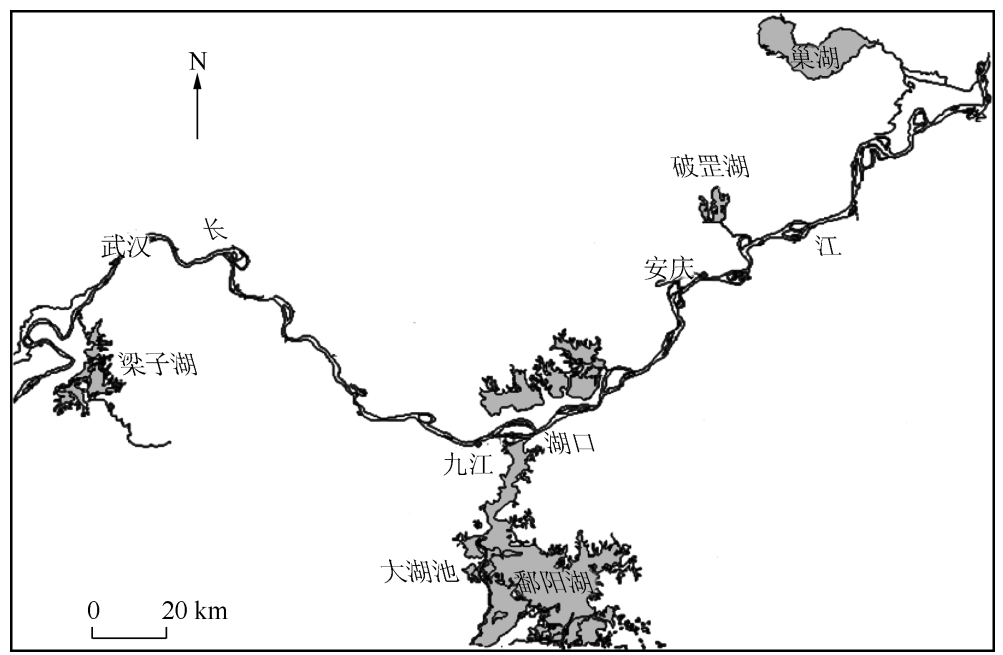

图 1 所研究湖泊位置

Fig. 1 Location of the studied lakes

巢湖: 跨合肥市、肥西县、肥东县和庐江县, 面积 $769.6 \mathrm{~km}^{2[15]}$. 为了防洪的需要,巢湖在 5 月份启闸放水 人江, 在 6 月中旬水位达到最低, 6 月中旬至 7 月受长江水位的影响, 水位开始上升,在 7 月中下旬达到最大 值,并在 7-10 月持续高水位,有小幅下降,进人 10 月长江水位开始降低,巢湖开始关闸蓄水,在 12 月水位 达到全年最大值. 巢湖全年水位波动幅度很小,2011 年波动幅度为 $1.2 \mathrm{~m}$.

破罡湖: 在安庆市东北郊广济圩内, 东隔广济圩大堤与长江紧邻, 面积 $60.0 \mathrm{~km}^{2[15]}$. 破罡湖水位在 6-7 月开始上升, 7 月中下旬达到最大值,并在 7-9 月持续高水位,随后缓慢下降. 破罡湖全年水位波动幅度小, 2011 年波动幅度为 $1.6 \mathrm{~m}$.

梁子湖: 位于长江南岸, 跨武昌县、鄂州市境, 面积 $304.3 \mathrm{~km}^{2[15]}$. 梁子湖水位在 7 月下旬达到最大值, 并 在 7-8 月持续高水位, 9 月上旬开始逐渐下降. 2011 年水位波动幅度为 $3.0 \mathrm{~m}$.

大湖池: 为鄱阳湖的一个子湖, 系由赣江、修水等河口三角洲天然堤封堵而形成的河间洼地湖, 面积 $36.7 \mathrm{~km}^{2[15]}$. 大湖池在夏季高水位时与鄱阳湖主体湖汇为一体, 洪水水位与鄱阳湖一致,在 6 月下旬达到最 大值,随着主体湖水位的下降在 7 月中下旬开始与主体湖断开,形成独立的湖泊,水位开始缓慢下降. 2011 年水位波动幅度为 $4.0 \mathrm{~m}$.

湖口 (鄱阳湖) : 为鄱阳湖人江水道,形状狭长. 湖口水位季节变化明显, 在 6 月下旬水位达到最大值, 随 后开始降低, 在 8-11 月出现了 3 次小洪峰,这是因为长江洪水倒灌鄱阳湖. 湖口水位年内波动幅度大,2011 年波动幅度为 $9.2 \mathrm{~m}$.

\section{2 样点设置、样品采集及实验室分析}

于 2011 年 $4 、 7 、 9$ 和 12 月开展样品采集. 每个湖泊选择 1 个较自然的湖滨带区域,在多年平均最低水位 线和最高水位线之间按高程梯度设置 4 个样点, 由低到高依次编为 I、II、III IV, 样点平均分布, 通过 GPS 定位并在样点附近选好固定参照物, 保证样点的一致. 测量样点到水面的距离及相对于水面的高度,通过采 
样当天的湖泊水位数据推算样点的高程, 再利用湖泊全年的水位数据计算样点各个时期的平均淹没深度以 及淹没时间. 样点采集区域湖滨带土地利用以农业为主, 湖滨带植被在巢湖以苔草和狗牙根为主; 破罡湖以 曧草和蛇床为主; 梁子湖以苶子草和狗牙根为主; 大湖池以苔草为主; 湖口以萎蒿和芦苇为主.

用直径 $5 \mathrm{~cm}$ 的土钻采集表层 $10 \mathrm{~cm}$ 的底质样品, 每个样点采 $2 \sim 3$ 个样品混合, 带回实验室分析, 测定 方法参考《土壤农业化学分析方法》 ${ }^{[16]}$.

测定参数包括含水率、粒径、 $\mathrm{pH}$ 值、有机质、总氮和总磷, 具体测定方法如下: 1) 底质含水率: 原样土, 烘 干法, $105^{\circ} \mathrm{C}$ 下烘 $24 \mathrm{~h} ; 2$ ) 粒径: 风干样, 吸管法, 送华中农业大学资源与环境学院测定 (只测定了 4 月份样 品);3) $\mathrm{pH}$ : 风干样, 过 $2 \mathrm{~mm}$ 篮, 按水土比 2.5:1 的比例, 将风干的底质样品和无二氧化碳水混成匀浆, 静置 $30 \mathrm{~min}$, 用 $\mathrm{pH}$ 计测定;4) 底质总氮 ( TN ) : 风干样, 研磨过 $0.149 \mathrm{~mm}$ 篎, 凯氏定氮仪测定;5) 底质总磷 $(\mathrm{TP})$ : 风干样, 研磨过 $0.149 \mathrm{~mm}$ 篮, 酸溶一钿锑抗比色法测定;6) 底质有机质 (OM) : 风干样, 研磨过 $0.149 \mathrm{~mm}$ 篎, 低温外热重铬酸钾氧化-比色法测定.

\section{2 结果}

\section{1 湖滨带底质理化特征}

所调查湖泊湖滨带底质质地主要分 3 类: 砂质壤土、黍壤土和壤土(图 2). 巢湖主要是砂质壤土, 破罡 湖、湖口、梁子湖主要是黏壤土或壤土, 大湖池主要是砂质黏壤土. 各湖泊湖滨带底质粉粒含量都较为接近, 决定底质质地的主要是砂粒 (或黏粒) 含量, 巢湖湖滨带底质含砂率最高 $(77.8 \%)$, 梁子湖最低 $(26.8 \%)$.

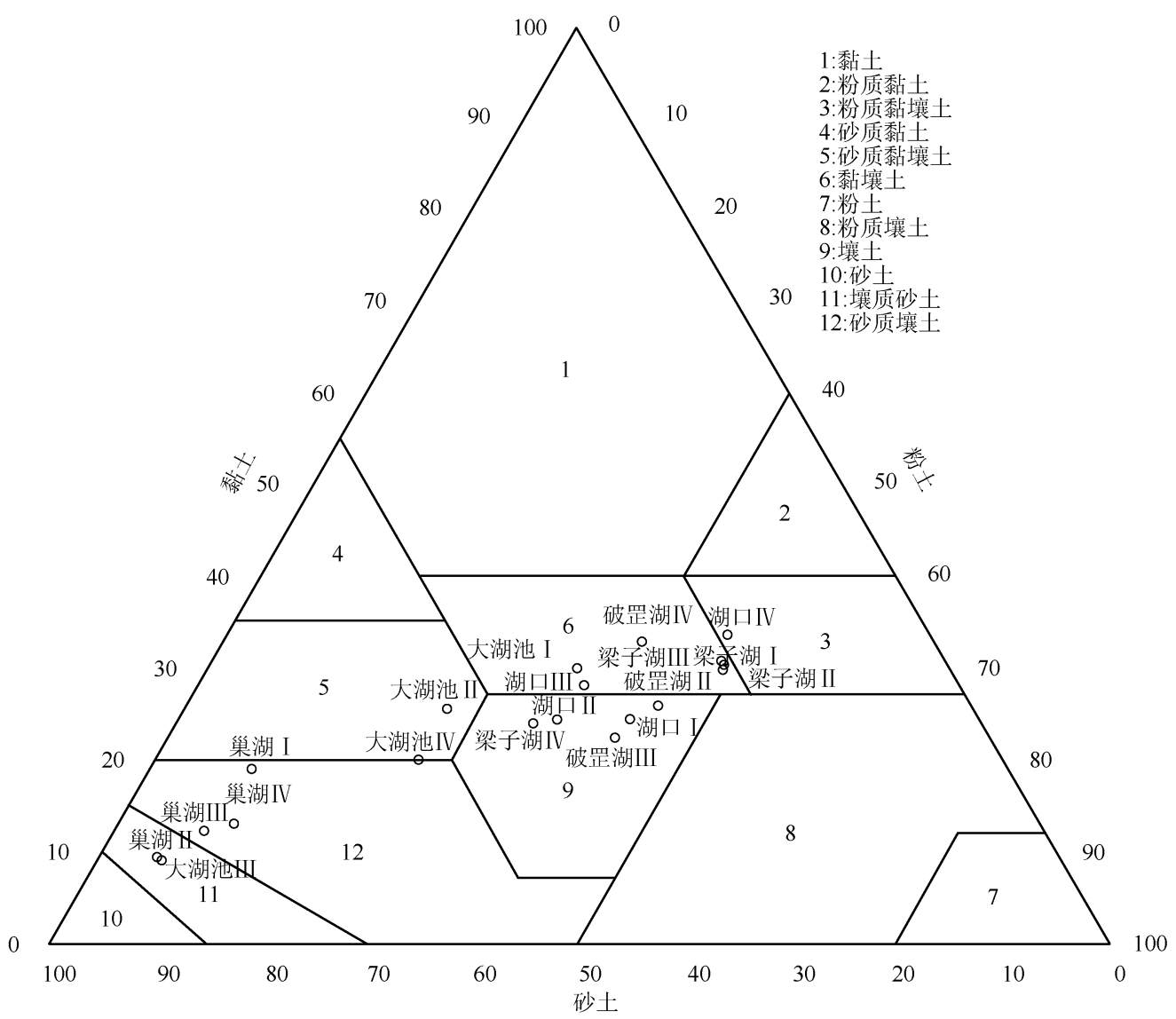

图 2 底质质地三角图

Fig. 2 Substrate texture triangle 
各湖泊湖滨带底质含水率差异不大, 破罡湖最高 $(26.3 \% \pm 2.5 \%$ (年均值 \pm 标准误,下同 $))$, 大湖池最 低 $(23.1 \% \pm 5.4 \%)$. 底质含水率与底质类型有关, 含砂率高的巢湖、大湖池年均含水率较低. 底质含水率沿 高程增加而减小 (图 3A), 大湖池和湖口变化幅度明显高于其它湖泊.

底质 $\mathrm{pH}$ 值在各湖泊间差异较大, 湖口 $\mathrm{pH}$ 值最大 $(8.13 \pm 0.14)$, 大湖池最小 $(5.27 \pm 0.19)$. 底质 $\mathrm{pH}$ 值 沿高程的变化不太明显, 且变化趋势在各湖泊间存在较大差异. 在巢湖和梁子湖, 底质 $\mathrm{pH}$ 值沿高程的增加 而减小; 在破罡湖 $\mathrm{pH}$ 沿高程的增加而增大; 在大湖池和湖口 $\mathrm{pH}$ 则先减小后增大 (图 $3 \mathrm{~B})$.

底质有机质含量在湖泊间也有较大差异. 巢湖有机质含量最高 $(28.89 \pm 4.03 \mathrm{mg} / \mathrm{g})$, 大湖池有机质含 量最低 $(19.64 \pm 2.70 \mathrm{mg} / \mathrm{g})$. 底质有机质含量沿高程变化明显, 除大湖池沿高程的增加而减小外, 其他湖泊 沿高程的增加呈先增大后减小的趋势 (图 3C). 有机质沿高程梯度变化最大的是巢湖 (变化率为 $288.9 \%$, 变 化率 $=($ 最大值 - 最小值 $) /$ 最小值 $)$,变化最小的是湖口 (变化率为 $32.2 \%$ ).

底质总氮含量在湖泊间有较大差异. 梁子湖总氮含量最高 $(1.17 \pm 0.19 \mathrm{mg} / \mathrm{g})$, 湖口总氮含量最低 $(0.72 \pm 0.11 \mathrm{mg} / \mathrm{g})$. 除梁子湖外, 底质总氮含量沿高程的增加也呈先增大后减小的趋势 (图 3D). 总氮沿高 程梯度变化最大的是巢湖 (变化率为 $717.4 \%$ ), 变化最小的是湖口 (变化率为 $39.5 \%$ ).
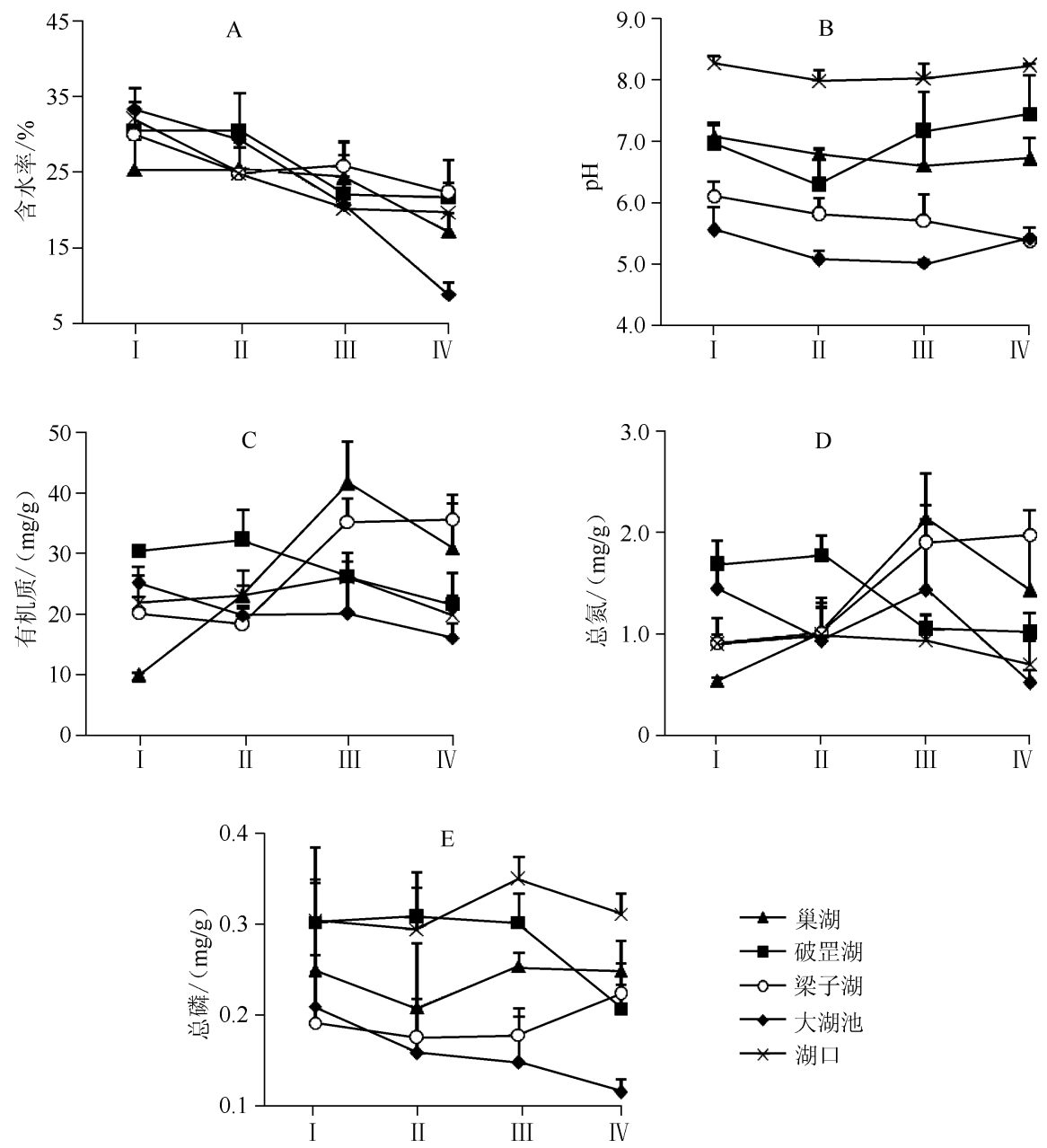

图 3 底质各理化参数 (年均值) 沿高程的变化

Fig. 3 Variation of physic-chemical parameters of substrate (annual mean) along the elevation 底质总磷含量在湖泊间也有较大差异. 破罡湖总磷含量最高 $(0.28 \pm 0.02 \mathrm{mg} / \mathrm{g})$, 大湖池总磷含量最低 
$(0.15 \pm 0.02 \mathrm{mg} / \mathrm{g})$. 随着高程的增加, 巢湖和梁子湖总磷含量先减小后增大, 破罡湖和湖口先增大后减小, 大湖池则呈减小趋势 (图 $3 \mathrm{E}$ ). 总磷含量沿高程梯度变化最大的是大湖池 (变化率为 $81.2 \%$ ), 变化最小的是 湖口 (变化率为 $18.7 \%$ ).

通过各参数间的相关分析, 发现总氮、总磷和有机质含量间有显著的正相关关系, 总磷含量与 $\mathrm{pH}$ 值在 夏季呈显著正相关, 总氮含量与含水率在春季呈显著正相关, 其余参数间关系不明显 (表 1 ).

\section{2 湖滨带底质理化特征季节动态}

湖滨带底质含水率季节变化明显, 除破罡湖外, 其他湖泊的变化趋势相似. 破罡湖含水率春季最低, 巢 湖和大湖池夏季最低, 梁子湖和湖口秋季最低 (图 4A). 除巢湖和破罡湖外, 其余湖泊底质 $\mathrm{pH}$ 值季节变化不 明显. 巢湖和破罡湖变化趋势相似,秋季 $\mathrm{pH}$ 值最高 (图 4B). 湖滨带有机质、总氮和总磷含量季节变化明显. 除巢湖外, 其他湖泊有机质和总氮含量变化趋势相似, 巢湖和梁子湖总磷含量变化趋势相似, 破罡湖、大湖 池和湖口总磷含量变化相似. 巢湖和破罡湖有机质含量在春季最低, 大湖池在夏季最低, 梁子湖和湖口则是 秋季最低 (图 4C) ; 所有湖泊总氮含量都是在夏季最低 (图 4D) ; 巢湖总磷含量春季最低, 破罡湖和湖口冬季 最低, 梁子湖夏季最低, 大湖池则是秋季最低 (图 4E).
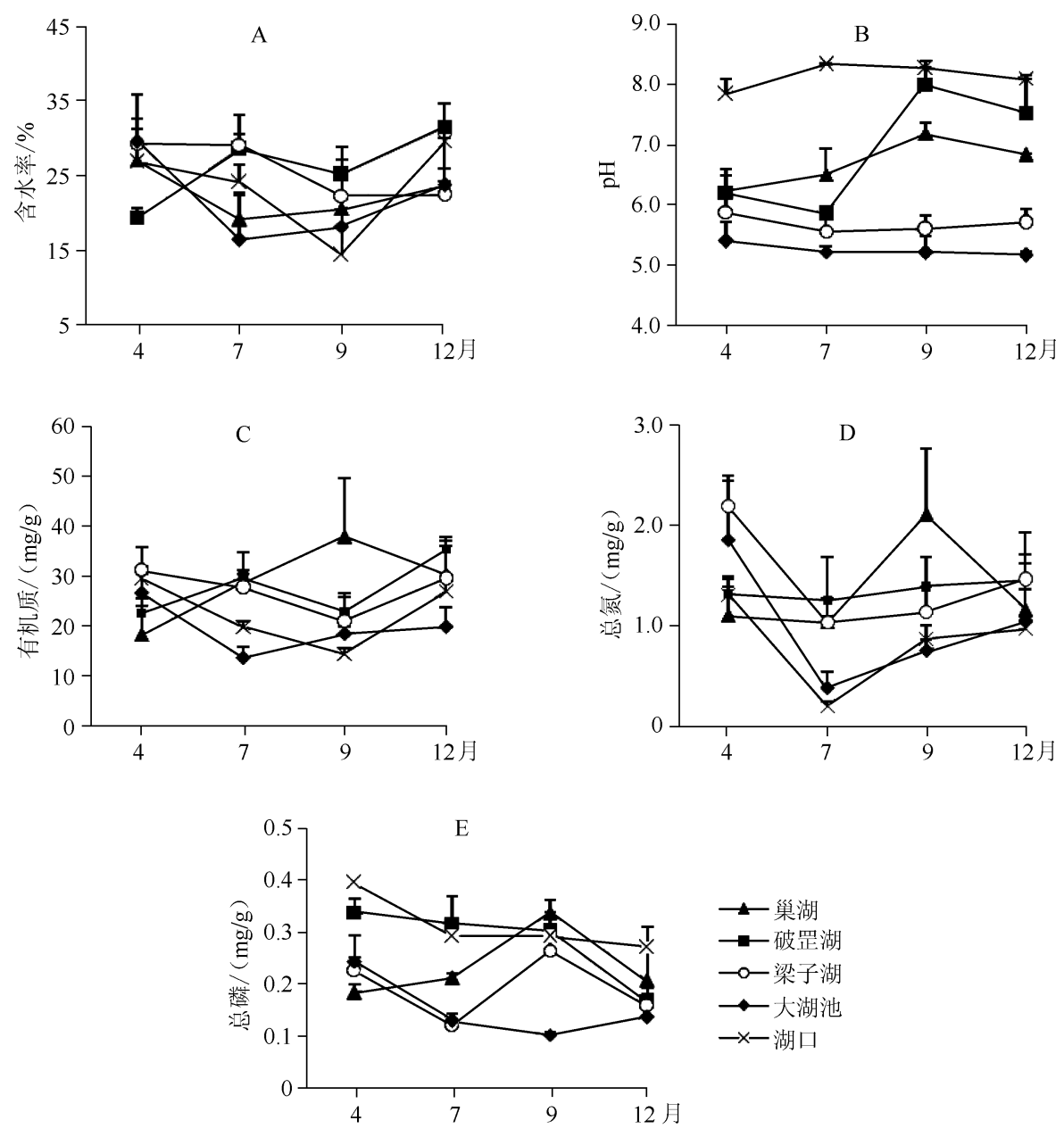

图 4 各湖泊湖滨带底质理化参数季节动态

Fig. 4 Seasonal dynamics of physic-chemical parameters of substrate in lakeshore of different lakes 
表 1 不同季节湖滨带底质参数之间的 Spearman 相关系数

Tab. 1 Spearman correlation coefficients among different parameters of substrate in lakeshore in different seasons

\begin{tabular}{rllrrrrrrrr}
\hline 季节 & $\mathrm{OM}-\mathrm{TN}$ & $\mathrm{OM}-\mathrm{TP}$ & $\mathrm{TN}-\mathrm{TP}$ & $\mathrm{pH}-\mathrm{OM}$ & $\mathrm{pH}-\mathrm{TN}$ & $\mathrm{pH}-\mathrm{TP}$ & $\mathrm{MC}-\mathrm{OM}$ & $\mathrm{MC}-\mathrm{TN}$ & $\mathrm{MC}-\mathrm{TP}$ & $\mathrm{MC}-\mathrm{pH}$ \\
\hline 春季 & $0.750^{* *}$ & $0.535^{*}$ & 0.244 & -0.017 & -0.409 & 0.383 & 0.211 & $0.556^{*}$ & -0.158 & -0.239 \\
夏季 & $0.856^{* *}$ & 0.194 & -0.035 & -0.022 & -0.215 & $0.574^{*}$ & 0.388 & 0.394 & -0.141 & -0.194 \\
秋季 & $0.904^{* *}$ & 0.033 & 0.262 & -0.272 & -0.061 & 0.421 & 0.192 & 0.205 & 0.217 & -0.153 \\
冬季 & $0.791^{* *}$ & $0.498^{*}$ & 0.319 & 0.244 & -0.119 & 0.368 & 0.428 & 0.249 & 0.182 & 0.154 \\
\hline
\end{tabular}

** 表示在 0.01 水平上极显著相关 (双尾检验), *表示在 0.05 水平上显著相关(双尾检验).

\section{3 湖滨带底质环境与水位波动之间的关系}

底质环境参数与水位波动幅度有一定的相关关系. 底质含水率、 $\mathrm{pH}$ 值和总磷变异系数在中等水位波动 幅度下最大; 有机质和总氮的变异系数也有相似规律,但在水位波动幅度最小时变异系数也较大 (图 5 ). 高 水位持续时间也是影响底质环境参数的重要因素. 夏季高水位持续时间越长, 底质 $\mathrm{pH}$ 值变化幅度就越大. 秋季高水位持续时间越长,越不利于底质有机质、总氮和总磷等营养物质的积累; 高水位持续时间超过 $20 \mathrm{~d}$ 即可导致总磷下降,持续时间超过 $50 \mathrm{~d}$ 则可导致总氮和有机质含量下降(图 6).
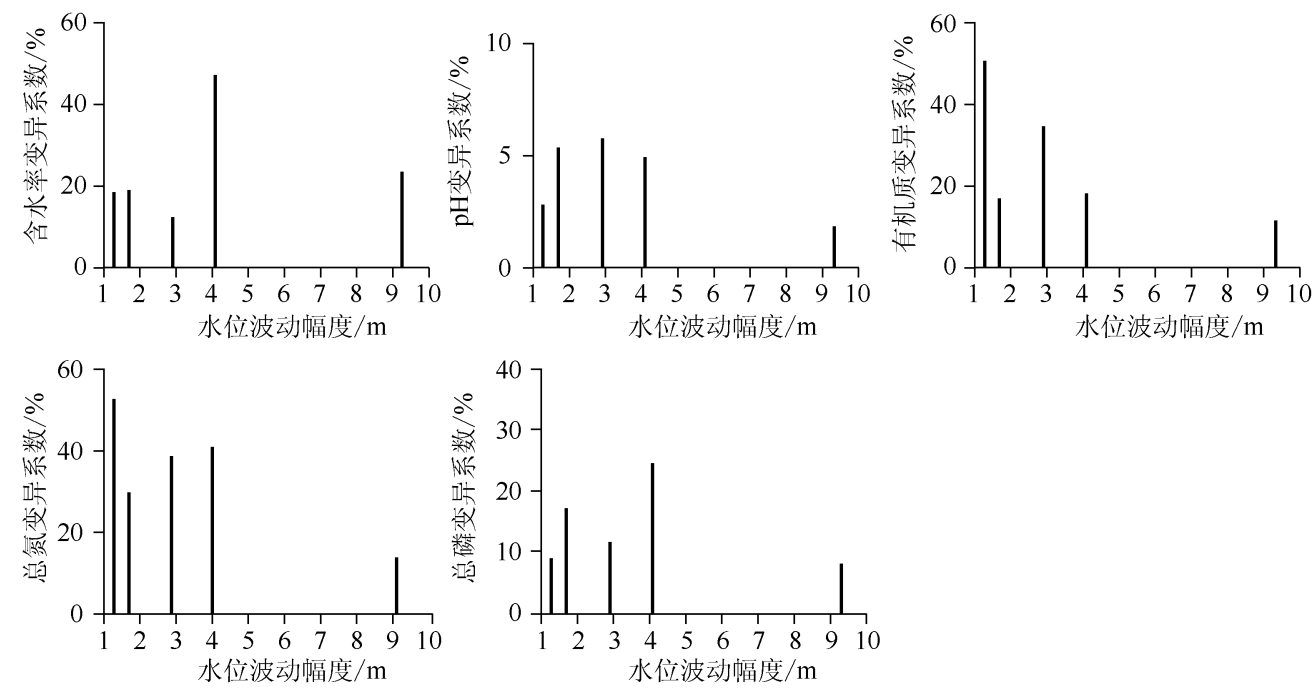

图 5 不同水位波动幅度湖泊湖滨带底质各参数沿高程的变异系数

Fig. 5 Coefficient of variation of substrate parameters along elevation in lakeshore of lakes with different amplitudes of water level fluctuations
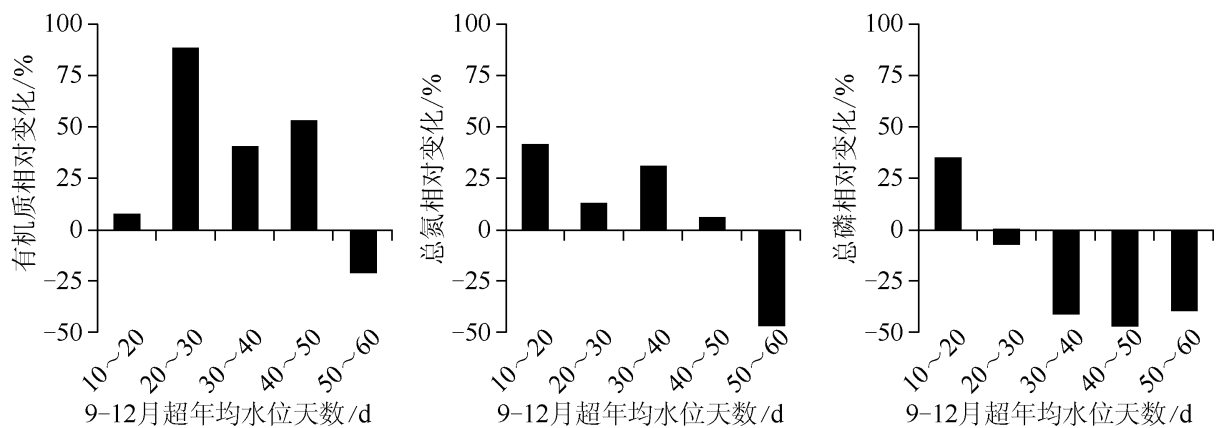

图 6 湖滨带底质有机质、总氮和总磷的相对变化 $(9-12$ 月)

Fig. 6 Relative changes of $\mathrm{OM}$, TN and TP contents in substrate in lakeshore from September to December 
底质营养盐含量与淹没时间和淹没深度呈显著负相关关系, 表明湖滨带淹没时间越长、淹没深度越大, 底质养分流失越快; 而底质 $\mathrm{pH}$ 值的变化则与淹没时间和淹没深度呈显著正相关关系. 9 月份部分底质参数 与 4-7 月淹没深度及淹没时间之间呈显著相关, 表明水位波动对底质环境的影响存在一定的时滞效应. 在 夏季,水位波动对底质 $\mathrm{pH}$ 值和总氮影响较大,在秋季对有机质和总磷影响较大 (表 2).

表 2 湖滨带底质参数与淹没时间、平均淹没深度之间的 Spearman 相关系数

Tab. 2 Spearman correlation coefficients between parameters of substrate in lakeshore and submergence time and average submergence depth

\begin{tabular}{|c|c|c|c|c|c|c|c|}
\hline & \multirow{2}{*}{ 底质参数 } & \multicolumn{2}{|c|}{$4-7$ 月 } & \multicolumn{2}{|c|}{$4-9$ 月 } & \multicolumn{2}{|c|}{$7-9$ 月 } \\
\hline & & 淹没时间 & 平均淹没深度 & 淹没时间 & 平均淹没深度 & 淹没时间 & 平均淹没深度 \\
\hline \multirow[t]{5}{*}{7 月 } & 含水率 & 0.468 & 0.229 & & & & \\
\hline & $\mathrm{pH}$ & 0.420 & 0.267 & & & & \\
\hline & $\mathrm{OM}$ & -0.411 & $-0.596^{*}$ & & & & \\
\hline & $\mathrm{TN}$ & -0.269 & $-0.574^{*}$ & & & & \\
\hline & $\mathrm{TP}$ & 0.138 & 0.145 & & & & \\
\hline \multirow[t]{5}{*}{$4-7$ 月 } & 相对含水率 & 0.174 & -0.093 & & & & \\
\hline & 相对 pH & $0.520^{*}$ & $0.514^{*}$ & & & & \\
\hline & 相对 OM & -0.205 & -0.488 & & & & \\
\hline & 相对 TN & $-0.508^{*}$ & $-0.671^{* *}$ & & & & \\
\hline & 相对 TP & -0.328 & -0.359 & & & & \\
\hline \multirow[t]{5}{*}{9 月 } & 含水率 & 0.116 & -0.096 & $0.457^{*}$ & 0.111 & $0.444^{*}$ & 0.332 \\
\hline & $\mathrm{pH}$ & 0.159 & 0.106 & 0.236 & 0.158 & 0.362 & $0.470^{*}$ \\
\hline & $\mathrm{OM}$ & -0.453 & $-0.626^{* *}$ & -0.353 & $-0.520^{*}$ & -0.303 & -0.370 \\
\hline & $\mathrm{TN}$ & -0.162 & -0.488 & -0.080 & -0.391 & -0.026 & -0.037 \\
\hline & $\mathrm{TP}$ & 0.363 & 0.035 & $0.602 * *$ & -0.041 & $0.727^{* *}$ & $0.647^{* *}$ \\
\hline \multirow[t]{5}{*}{ 7-9月 } & 相对含水率 & -0.248 & -0.347 & 0.009 & -0.382 & 0.162 & -0.027 \\
\hline & 相对 pH & -0.453 & -0.489 & -0.257 & $-0.521 *$ & -0.096 & -0.203 \\
\hline & 相对 OM & $-0.658 * *$ & $-0.503^{*}$ & $-0.720^{* *}$ & -0.432 & $-0.686^{* *}$ & $-0.672^{* *}$ \\
\hline & 相对 TN & 0.012 & 0.153 & -0.281 & 0.188 & -0.304 & -0.075 \\
\hline & 相对 TP & 0.356 & -0.100 & 0.347 & -0.156 & 0.373 & 0.343 \\
\hline \multirow[t]{5}{*}{$4-9$ 月 } & 相对含水率 & -0.205 & -0.361 & 0.243 & -0.166 & 0.333 & 0.184 \\
\hline & 相对 pH & -0.163 & -0.205 & 0.036 & -0.356 & 0.263 & 0.162 \\
\hline & 相对 OM & $-0.642^{* *}$ & $-0.812^{* *}$ & -0.127 & $-0.671^{* *}$ & -0.005 & -0.221 \\
\hline & 相对 TN & -0.356 & -0.494 & -0.055 & -0.441 & 0.109 & 0.071 \\
\hline & 相对 TP & -0.024 & -0.332 & 0.280 & $-0.444^{*}$ & 0.440 & 0.250 \\
\hline
\end{tabular}

**表示在 0.01 水平上极显著相关 (双尾检验)，*表示在 0.05 水平上显著相关 (双尾检验).

\section{3 讨论}

本文报道了水位波动对湖滨带底质环境参数的影响, 结果可为湖滨带生态修复提供参考. 研究发现湖 滨带底质环境参数沿高程梯度的变化及季节动态变化均较明显, 二者均与水位波动有较大的关系. 水位波 动对底质 $\mathrm{pH}$ 值有较大影响, 尤其是酸性底质, 淹没会使其 $\mathrm{pH}$ 值变大, 并且淹没的深度越大、时间越长则 $\mathrm{pH}$ 值变化越大. 这是因为湖滨带底质在周期性淹水的情况下, 一方面氧气减少, 另一方面厌氧微生物产生多种 还原性气体, 导致底质氧化还原电位下降, 淹没深度越深、时间越长, 氧化还原电位下降越明显 ${ }^{[17-19]}$, 随着氧 化还原电位的降低 $\mathrm{pH}$ 值增大 ${ }^{[20-21]}$.

水位波动对湖滨带底质的营养元素含量也有重要的影响. 水位上涨可导致湖滨带底质有机质含量下 降. 研究表明一定的淹没会促进有机质的矿化 ${ }^{[22]}$, 水位上升会导致湖滨带底质中可溶性有机碳含量增 
加 ${ }^{[23-24]}$, 在频繁波动的情况下, 易流失进人水体. 本研究表明, 高水位持续时间过长不利于冬季有机质的积 累, 这可能与高水位持续时间过长导致植物生物量减少、有机质来源减少有关. 对三峡库区消落带的研究也 表明,经过淹水的土壤中有机物质含量显著低于未淹水土壤 ${ }^{[25]}$.

水位上升导致湖滨带底质总氮、总磷含量下降, 长期高水位不利于氮、磷的积累. 一定的淹没会加速氮 的矿化作用 ${ }^{[26-27]}$, 长期的高水位则会使底质氨氮含量增加、硝态氮含量减少, 最终会导致湖滨带底质氮的流 失 ${ }^{[28]}$. 在高水位时, 底质中的磷会因处于还原性环境而以磷酸盐的形式被释放出来, 底质对磷的吸附能力减 弱, 水位波动导致的底质再悬浮也会增加磷释放进人水体的通量 ${ }^{[29-31]}$; 低水位时底质重新暴露, 对磷的吸附 能力增强 ${ }^{[32]}$.

水位波动的幅度、淹没深度、高水位持续时间等对湖滨带底质有较大影响. 在中等波动幅度下,湖滨带 底质环境参数变化最大, 表明此时底质异质性也较大, 在一定程度上支持了中度干扰假说 ${ }^{[33]}$. 长期高水位使 湖滨带底质营养盐尤其是磷被释放进人水体, 导致湖滨带底质对污染物的吸纳能力下降, 不利于湖泊富营 养化治理. 底质在植物生长、发育的过程中有着重要的作用, 能为植物提供水分、养分以及稳定的环境 ${ }^{[17]}$, 水 位波动引起底质环境变化, 进而可对湖滨带植物的生长、分布等产生影响. 例如, 冬、春季持续高水位导致底 质 $\mathrm{pH}$ 值不稳定、营养盐流失, 不利于植物的萌发和生长 ${ }^{[34-35]}$.

依据上述研究结果, 对湖滨带生态修复及管理提出几点建议:1) 对于人工控制水位的湖泊, 应保持适当 的水位波动幅度以提高湖滨带底质异质性, 同时避免长期持续高水位;2）冬、春季若出现持续高水位,应对 底质氧化还原电位进行调节, 维持 $\mathrm{pH}$ 值稳定, 并采取适当措施加快有机质分解.

\section{4 参考文献}

[ 1 ] Coops H, Beklioglu M, Crisman TL. The role of water-level fluctuations in shallow lake ecosystems-workshop conclusions. Hydrobiologia, 2003 , 506-509:23-27.

[ 2 ] Wantzen KM, Rothhaupt KO, Mörtl M et al. Ecological effects of water-level fluctuations in lakes: an urgent issue. Hydrobiologia, 2008, $613: 1-4$.

[ 3 ] Leira M, Cantonati M. Effects of water-level fluctuations on lakes: an annotatedbibliography. Hydrobiologia, 2008,613 : 171-184.

[ 4 ] 王洪铸. 湖滨带的基本概念. 长江流域资源与环境,2012,21(2):1-2.

[ 5 ] 尹澄清. 内陆水一陆地交错带的生态功能及其保护与开发前景. 生态学报, 1995,15(3):331-335.

[ 6 ] 颜昌宙,金相灿,赵景柱等. 湖滨带的功能及其管理. 生态环境,2005,14(2):294-298.

[ 7 ] Naiman RJ, Décamps H. The ecology of interfaces: riparian zones. Ann Rev Ecol Syst , 1997, 28:621-658.

[ 8 ] Venkatachalam A, Radhakrishnan J, Yamaji E. Impact of riparian buffer zones on water quality and associated management considerations. Ecological Engineering, 2005, 24 : 517-523.

[ 9 ] Furey PC, Nordin RN, Mazumder A. Water level drawdown affects physical and biogeochemical properties of littoral sediments of a reservoir and a natural lake. Lake and Reservoir Management, 2004, 20 : 280-295.

[10] 刘 永, 郭怀成, 周 丰等. 湖泊水位变动对水生植被的影响机理及其调控方法. 生态学报, 2006, 26(9): 3117-3126.

[11] Flynn KM, Mendelssohn IA, Wilsey BJ. The effect of water level management on the soils and vegetation of two coastal Louisiana marshes. Wetlands Ecology and Management, 1999, 7:193-218.

[12] Battaglia LL, Collins BS. Linking hydroperiod and vegetation response in Carolina bay wetlands. Plant Ecology, 2006, 184 (1) : 173-185.

[13] 程瑞梅,王晓荣,肖文发等. 消落带研究进展. 林业科学,2006,46(4):111-119.

[14] 郭劲松,黄轩民,张 涁等. 三峡库区消落带土壤有机质和全氮含量分布特征. 湖泊科学,2012,24(2):213-219.

[15］王苏民,窦鸿身. 中国湖泊志. 北京:科学出版社,1998.

[16] 鲁如坤.土壤农业化学分析方法. 北京:中国农业科技出版社,1999.

[17］田应兵,宋光显,艾天成. 湿地土壤及其生态功能. 生态学杂志,2002,21(6):31-39.

[18] Hseu ZY, Chen ZS. Saturation, reduction and redoxmorphology of seasonally flooded Alfisols in Taiwan. Soil Science Society of America, 1996, 60 : $941-949$. 
[19] Reynolds JG, Naylor DV, Fendorf SE. Arsenicsorption in phosphate-amended soils during flooding and subsequent aeration. Soil Science Society of America, 1999, 63: 1149-1156.

[20] Narteh LT, Sahrawat KL. Influence of flooding on electrochemical and chemical properties of West African soils. Geoder$m a, 1999,87$ : 179-207.

[21] 唐罗忠,生原喜久雄,户田浩人等. 湿地林土壤的 $\mathrm{Fe}^{2+}$, Eh 及 $\mathrm{pH}$ 值的变化. 生态学报, 2005,25(1) : 103-107.

[22] Fierer N, Schimel JP. A proposed mechanism for the pulse in carbon dioxide production commonly observed following the rapid rewetting of a dry soil. Soil Science Society of America, 2003 , 67 : 798-805.

[23] Wang FL, Bettany JR. Influence of freeze-thaw and flooding on theloss of soluble organic carbon and carbon dioxide from soil. Journal of Environmental Quality, 1993, 22 : 709-714.

[24] 李忠佩, 张桃林, 陈碧云. 可溶性有机碳的含量动态及其与土壤有机碳矿化的关系. 土壤学报, 2004,41 (4): 543-552.

[25] 常 超,谢宗强,熊高明等.三峡水库蓄水对消落带土壤理化性质的影响. 自然资源学报,2011,26(7):1236-1244.

[26] Venterink HO, Davidsson TE, Kiehl K et al. Impact of drying and re-wetting on N, P and K dynamics in a wetland soil. Plant and Soil, 2002, 243: 119-130.

[27] Stanley EH, Boulton AJ. Hyporheic processes during flooding and drying in a Sonoran desert stream. 1. Hydrologic andchemical dynamics. Archiv fuir Hydrobiologie, 1995 ,134: 1-26.

[28] Qiu S, McComb AJ. Drying-induced stimulation of ammonium release and nitrification in reflooded lake sediment. Marineand Freshwater Research, 1996,47: 531-536.

[29] Baldwin DS, Mitchell AM. The effects of drying and re-flooding on the sediment and soil nutrient dynamics of lowland river-floodplain systems: a synthesis. Regulated Rivers : Research and Management, 2000, 16(5) : 457-467.

[30 ] Litaor MI, Reichmann O, Auerswald K et al. Sorption characteristics of phosphorus in peat soils of a semiarid altered wetland. Soil Science Society of America, 2005, 69:1658-1665.

[31] Søndergaard M, Kristensen P, Jeppesen E. Phosphorus release from resuspended sediment in the shallow and wind-exposed Lake Arres $\varnothing$, Denmark. Hydrobiologia, 1992, 228: 91-99.

[32] Baldwin DS. Effects of exposure to air and subsequent drying on the phosphate sorption characteristics of sediments from a eutrophic reservoir. Limnology and Oceanography, 1996, 41(8) : 1725-1732.

[33] Amoros C, Bornette G. Connectivity and biocomplexity in waterbodies of riverine floodplains. Freshwater Biology, 2002, 47: 761-776.

[34] 徐治国, 何 岩, 闫百兴等. 植物 $\mathrm{N} / \mathrm{P}$ 与土壤 $\mathrm{pH}$ 值对湿地植物物种丰富度的影响. 中国环境科学, 2006,26(3): 346-349.

[35] 马红媛, 梁正伟. 不同 $\mathrm{pH}$ 值土壤及其浸提液对羊草种子萌发和幼苗生长的影响. 植物学通报, 2007,24(2): 181-188. 